\title{
Evaluation of service quality by using fuzzy MCDM: A case study in Iranian health-care centers
}

\author{
Leili Afkham $^{\mathrm{a}^{*}}$, Farshid Abdi ${ }^{\mathrm{a}}$ and Alireza Rashidi Komijan ${ }^{\mathrm{b}}$
}

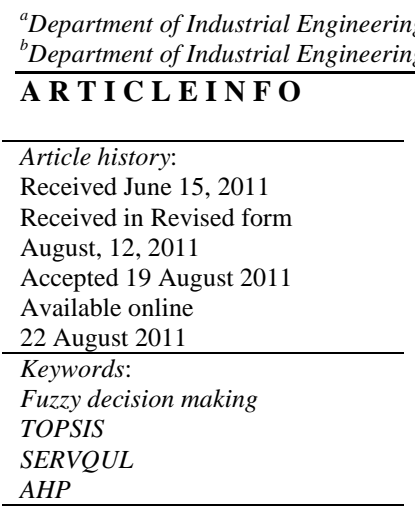
\begin{abstract}
A B S T R A C T
Service quality plays an important role in health care systems since hospitals are responsible for people's lives. This study presents an effective approach for evaluating and comparing service qualities of four hospitals. Service quality consists of different attributes and many of them are intangible and difficult to measure. Therefore, we propose a fuzzy method to resolve the ambiguity of the concepts, which are associated with human judgments. SERVQUAL model is used to evaluate the respondents' judgments of service quality and multi attribute decision making approach is implemented for the comparison among hospitals. The paper use analytical hierarchy process (AHP) for obtaining criteria weight and TOPSIS for ranking the cases.
\end{abstract}

(c) 2012 Growing Science Ltd. All rights reserved.

\section{Introduction}

The increasing emphasis on the quality of healthcare services is because of the benefits of the both sides of proposition; in fact, both patients and healthcare organizations take advantage of it. Today, quality management is one of the most important aspects of senior management performance. Since perceptions of service quality are considered as the key elements of preferences for hospital service consumers, hospital managers need valid and practical psychological rates to measure the quality of service. There have been various works on this subject to use qualitative and quantitative methods to measure the quality of service. SERVQUAL is one of the most famous measurement tools used in health service industries.

The measurement of dimensions and components of SERVQUAL in non-fuzzy and certain environments has been criticized for two reasons:

1) These methods have not considered people's judgments in certain numbers and the judgmental values change when they are turned into numbers.

2) Subjectivism, judgments, selection and priority of evaluators have great impacts on the results of these methods.

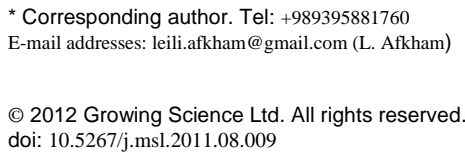


In spite of the fact that so many studies have been focused on the gap between the consumers' points of view and suppliers' points of view on service quality, there are limited studies to determine which dimension is more important and more effective for hospitals. There are so many limitations in the judgments about priority of criteria in service quality. Traditional statistical methods have so many problems with these limitations. In fact, statistical methods are not able to investigate the following two major problems (Wu et al. ,2004):

1) Describing the dimensions of service quality in heterogeneous matrixes in order to have an overall evaluation of effectiveness of hospitals in comparison with other hospitals and getting the final grade of each hospital as a result.

2) Recognition the status of each hospital and determining the criteria that is more important than others in the quality system of hospitals in Iran.

According to the studies, the researches, which have been done about hospital's service quality in Iran were not comprehensive and none of them has analyzed the patients' opinions in a fuzzy model.

The practical objectives of this research are as follow,

1) to determine the priority of dimensions of the quality of services of hospital from consumers' point of view,

2) to determine the strengths and weaknesses of service quality in each hospital in society,

3) to classify the hospitals based on their quality,

4) and to provide strategies for improving the service quality of each hospital.

\section{Theoretical background and conceptual framework}

\subsection{SERVQUAL ${ }^{1}$}

The service quality of healthcare organizations impacts the behavior of patients in terms of their satisfaction, return, selection, use, etc. (Lafond, 1996; Magi, 1996; Guldner, 1993; Shawyer et al., 1996; Gilbert et al., 1992; Zeithaml \& Bitner, 2000). Evaluation of a service quality is a challenging task and normally there are two major health issues are associated with it. The first thing is to know who measures the quality and by which criteria. Historically developing quality standards have been entrusted to medical professionals, but the recent researches in developed countries emphasis on the importance of patients approach (O’Connor et al., 1994).

However, some people still believe that the patients cannot make proper judgment on the quality and their opinions are very subjective. According to Peterson (1988), it is not important that patient thinks properly or not, only patient's feeling is important, even if it is no true.

Parasuraman et al. (1985) present a model for measuring service quality, which calculates the gap between the expectations and the perceptions of consumers. Primary works of these researchers were drawn by deep and analytical interviews with concentrated group of executive officers and consumers of four service industries. Their first attempt was the ten dimensional concept of the quality of service. Then, Parasuraman et al. (1988) presented a five dimensional tool by exploratory factor analysis of a 97-item questionnaire. Five dimensions of this model are assurance, responsiveness, reliability, empathy and tangibles. This questionnaire has 22 items; each of these items are in two forms: expectations and perceptions (performances). Therefore, this 44-question tool can measure the quality of service from consumers' approach easily. SERVQUAL was used in so many service concepts, recently. It was used in tourism management (Tsaura et al., 2002), health care (Michael et al., 2001; Wu et al., 2007), retail (Dabholkar et al.,1996; Parikh, 2005), universities (Ham, 2003), banking (Wang et al., 2002).

\subsection{Fuzzy Theory}

Fuzzy sets and fuzzy logic are effective tools for modeling complex systems in the absence of certain and complete information. Subjective judgments of experts based on fuzzy techniques have better

\footnotetext{
${ }^{1}$ SERVice QUALity
} 
results than concrete application of incorrect information. Since linguistic terms are usually used for expressing the non-exact and subjective opinions of decision-makers, in this research we use them in order to simplify the subjective evaluations of respondents (Herrera \& Viedma, 2000; Yeh et al., 1999a; Zadeh, 1975; Zimmerman, 1996).

A set of linguistic terms is defined as $S=\{$ SDA: Strongly Disagree, DA : Disagree, LDA: Little Disagree, NC: No Comment, LA: Little Agree, A: Agree, SA: Strongly Agree\}.

\subsection{Fuzzy multi criteria decision making}

The decision making in which various and opposite quality factors are being evaluated and the suitable solution is selected between a few options is called multi criteria decision making (MCDM) and the decision making in which evaluated values and factor weights are presented by fuzzy numbers or linguistic variables is called fuzzy multi criteria decision making (FMCDM). Since the first time zadeh (1965) brought up the theory of fuzzy sets and Bellman \& Zadeh (1970) described the method of decision making in fuzzy environment, the number of studies in unreliable and fuzzy environment have been increased (Ryan \& Trauer, 2003; Tsau et al., 2002; Chien \& Tsai,2000; Nakamori et al., 1997; Viswanathan, 1999; Xia et al., 2000; Hutchinson, 1998).

The subject of service quality is mixed with fuzzy uncertain expressions such as behavior, taste and environment and evaluations must be presented by fuzzy sets (Yeh \& Kuo, 2003; Zimmerma,1996; Prascevic \& Petrovic, 1996-8). Most of the studies have mixed the theory of fuzzy sets with controlling the quality (Roger et al.,1999; Wang, 2002; Ufec \& Ahmet, 2002; Yeh \& Cheng, 2002; Liou \& Chen, 2006), measurement of quality (Zhou et al., 2001; Yeh \& Kuo, 2003; Benitez, 2004; Andaleeb, 2001), evaluation of performance (Hu, 2009; Tsai et al., 2008) and product design (Hsiao,1998).

\section{4. $A H P^{2}$}

We can get the weight function of each objective by different methods such as AHP. For the first time this method was innovated by Saaty (1980). This method mixes the opinions and evaluations of expert people and turn a complex decision making system into a hierarchical one. Then the evaluation method is applied by proportional scale so that it could continue its applications by proportional importance of pair comparisons between criteria. This method breaks down the complex hierarchical problems from upper level to the lower ones. We can calculate the proportional weight of criteria by using the special vector of pair comparisons matrix. Therefore, this research uses this method to evaluate the proportional weight of five criteria in measuring the quality of service.

\subsection{TOPSIS}

Several methods such as SAW ${ }^{3}$, PROMETHEE $^{4}$, TOPSIS ${ }^{5}$, and ELECTRE ${ }^{6}$ are used in multi criteria decision making. For the first time TOPSIS was presented by Hwang \& Yoon (1981).The logic of this method is the definition of ideal solution and negative ideal solution. The ideal solution is a solution, which maximizes the criteria of benefits and minimizes the criteria of expenses. The negative ideal solution is a solution, which maximizes the cost criteria and minimizes the benefit criteria. Optimum solution is the one, which has the least distance to the ideal solution and the most distance to the negative ideal solution. Classification of options is based on its proportional similarity

\footnotetext{
${ }^{2}$ Analyctic Hierarchy Process

${ }^{3}$ Simple Additive Weighting

${ }^{4}$ Preference Ranking Organisation METHod for Enrichment Evaluations

${ }^{5}$ Technique for Order Preference by Similarity to Ideal Solution

${ }^{6}$ ELimination Et Choix Traduisant la REalité (ELimination and Choice Expressing REality)
} 
to the ideal solution. This concept is very common in decision making contexts (Athanassopoulos \& Podinovski, 1997; Yeh et al., 2000; Chen \& Hwang, 1991; Zeleny, 1998).

Total framework of this research is as following:

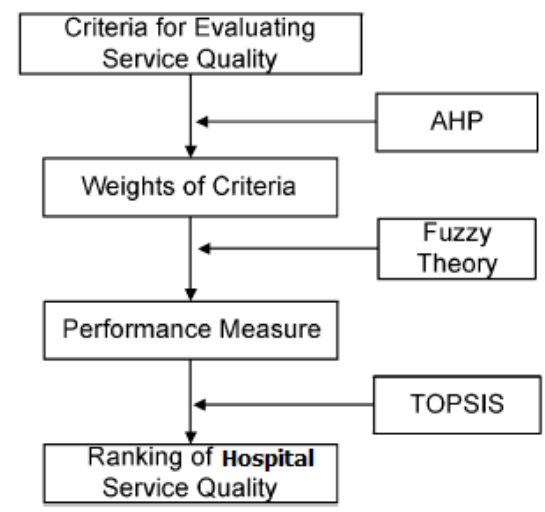

\section{Methodology}

Fig. 1 . Total framework of the study

The questionnaire of this research is the one of the SERVQUAL model, which is used in health service industries. The main questionnaire consists of 55 questions, six questions were removed after receiving experts' feedbacks, and the remaining 49 questions were distributed among respondents.

\subsection{Reliability and Validity}

Factor analysis was used in order to investigate the reliability of this questionnaire and then Cronbach Alpha (1951) coefficients of 5 indexes of questionnaire were measured. Table 1 shows the results of factor analysis. This table shows that the standard factor loading is significant for all the variables.

Table 1

Factor loading of variables

\begin{tabular}{llllllllll}
\hline Var & Value & Var & Value & Var & Value & Var & Value & Var & Value \\
\hline var001 & 0.61987 & var011 & 0.946579 & var021 & 0.908295 & var031 & 0.971682 & var041 & 0.889858 \\
var002 & 0.970117 & var012 & 0.686415 & var022 & 0.896114 & var032 & 0.808446 & var042 & 0.850236 \\
var003 & 0.932306 & var013 & 0.941049 & var023 & 0.877422 & var033 & 0.51268 & var043 & 0.932967 \\
var004 & 0.659221 & var014 & 0.786113 & var024 & 0.763805 & var034 & 0.724791 & var044 & 0.804022 \\
var005 & 0.675237 & var015 & 0.934925 & var025 & 0.836485 & var035 & 0.967575 & var045 & 0.937619 \\
var006 & 0.902718 & var016 & 0.479458 & var026 & 0.818208 & var036 & 0.935191 & var046 & 0.796695 \\
var007 & 0.747063 & var017 & 0.963407 & var027 & 0.562218 & var037 & 0.785121 & var047 & 0.948825 \\
var008 & 0.669701 & var018 & 0.987321 & var028 & 0.94149 & var038 & 0.85431 & var048 & 0.765985 \\
var009 & 0.95715 & var019 & 0.76154 & var029 & 0.747996 & var039 & 0.985701 & var049 & 0.696688 \\
var010 & 0.518181 & var020 & 0.642336 & var030 & 0.985286 & var040 & 0.979913 & & \\
\hline
\end{tabular}

Cronbach Alpha of the tangibles part of the questionnaire (the first 13 questions) is 0.91, reliability (the 4 questions afterward) is 0.85 , responsiveness (12 questions afterward) is 0.75 , assurance (9 questions afterward) is 0.8 and at last the empathy dimension of the questionnaire (the last 11 questions) is 0.86 .

\subsection{Sample}

This research was done in 4 hospitals in Shiraz and we classified these four hospitals in groups A, B, $\mathrm{C}$, D. The questionnaire of SERVQUL was distributed between the patients and the visitors of these four hospitals. The number of people was specified by the use of the formula of infinite sample (the number of patients was approximately definite but the number of their visitors was not exactly 
definite) and error of $5 \%$. We have used the following formula to calculate the minimum number of sample size,

$$
n=z_{\alpha / 2}^{2} \frac{p \times q}{\varepsilon^{2}},
$$

where $n$ is the number of sample size, $p=1-q$ represents the yes/no categories, $z_{\alpha / 2}$ is CDF of normal distribution and finally $\varepsilon$ is the error term. Since we have $p=0.5, z_{\alpha / 2}=1.96$ and $\varepsilon=0.03$ the number of sample size is calculated as $n=385$.

We have distributed 100 questionnaires in each hospital and total of 400 questionnaires were distributed in four hospitals where 260 of them were filled and the responsive rate was $65 \%$.

\subsection{Weight of criterions}

We used the AHP method by applying expert choice to get the weight of criteria. According to the pair comparisons performed by 30 people, we applied group AHP and its process is as follows,

$D=\left\|a_{i j}=w_{i} / w_{j}\right\|$

$a_{i j}^{\prime}=\left(\prod_{l=1}^{k} a_{i j l}\right)^{1 / k}$

$l=1, \cdots, k ; i, j=1, \cdots, n ; i \neq j$

where $k$ is the number of decision makers. When the consistency ratio is less than 0.1 we group decision makers' opinions to reach better compatibility. Results show that empathy with the weight coefficient of 0.292 is the most important criterion, and then the weight coefficients of the tangibles, assurance, reliability and responsiveness are $0.279,0.146,0.144$, and 0.14 , respectively. The inconsistency ratio is 0.00348 , which is well below the value of 0.1 .

\subsection{Service Quality}

In this section in order to evaluate the opinions of respondents, linguistic expressions were converted to triangular fuzzy numbers as follows,
SDA: Strongly Disagree $(0,0,0.15)$
DA: Disagree $(0,0.15,0.3)$
LDA: Little Disagree $(0.15,0.3,0.5)$
NC: No Comment $(0.3,0.5,0.65)$
LA: Little Agree $(0.5,0.65,0.8)$
A: Agree $(0.65,0.8,1)$
SA: Strongly Agree $(0.8,1,1)$

Then the necessary calculations were done by Microsoft excel software presented in Table 2.

Table 2

Fuzzy calculations of quality in each hospital

\begin{tabular}{lllll}
\hline & Hospital A & Hospital B & Hospital C & Hospital D \\
\hline Tangibles & $(0.4058,0.559,0.7146)$ & $(0.3713,0.5178,0.6680)$ & $(0.3324,0.4796,0.6322)$ & $(0.3320,0.4772,0.6307)$ \\
Reliability & $(0.3764,0.5257,0.6791)$ & $(0.359,0.5054,0.6554)$ & $(0.3466,0.4955,0.6498)$ & $(0.330,0.4710,0.6242)$ \\
Responsive-ness & $(0.3701,0.5178,0.6733)$ & $(0.3417,0.4866,0.6394)$ & $(0.3624,0.5123,0.667)$ & $(0.3630,0.512,0.6705)$ \\
Assurance & $(0.3911,0.5388,0.6938)$ & $(0.3422,0.4935,0.65)$ & $(0.3457,0.4892,0.6462)$ & $(0.3767,0.5214,0.6815)$ \\
Empathy & $(0.3413,0.4858,0.6434)$ & $(0.3503,0.494,0.6517)$ & $(0.3359,0.4780,0.6348)$ & $(0.3498,0.4922,0.6461)$ \\
\hline
\end{tabular}

\subsubsection{Defuzzification}

Then we converted the fuzzy triangular numbers into certain ones. In this research we used the method developed by Liou and Wang $(1992,1994)$ to defuzzy the triangular fuzzy numbers. Table 3 summarizes the numbers in crisp form. 
Table 3

Crisp values of each criterion in hospitals

\begin{tabular}{lllll}
\hline & Hospital A & Hospital B & Hospital C & Hospital D \\
\hline Tangibles & 0.5595755 & 0.51871775 & 0.48096425 & 0.47925975 \\
Reliability & 0.52674275 & 0.50625025 & 0.49682975 & 0.47416975 \\
Responsiveness & 0.51975125 & 0.488559 & 0.513572 & 0.51435925 \\
Assurance & 0.540625 & 0.494815 & 0.4925725 & 0.5252285 \\
Empathy & 0.489117 & 0.49776525 & 0.481703 & 0.4950805 \\
\hline
\end{tabular}

Then by getting certain values of each index for each hospital and by using the weights of all of the criteria obtained by AHP method, we get the final classification of hospitals.

\subsection{TOPSIS calculations}

Algorithm of the TOPSIS method evaluates the decision matrix, which consists of $j$ option and $n$ criteria. In our case the decision making matrix is as follow,

\section{Table 4}

Decision matrix of the study

\begin{tabular}{llllll}
\hline & Tangibles & Reliability & Responsiveness & Assurance & Empathy \\
\hline Hospital A & 0.5595755 & 0.52674275 & 0.51975125 & 0.540625 & 0.489117 \\
Hospital B & 0.51871775 & 0.50625025 & 0.488559 & 0.494815 & 0.49776525 \\
Hospital C & 0.48096425 & 0.49682975 & 0.513572 & 0.4925725 & 0.481703 \\
Hospital D & 0.47925975 & 0.47416975 & 0.51435925 & 0.5252285 & 0.4950805 \\
\hline
\end{tabular}

First step: We calculate the normalized decision matrix by the follows,

$$
r_{i j}=\frac{f_{i j}}{\sqrt{\sum_{j=1}^{n} f_{i j}^{2}}}, j=1, \cdots, J ; i=1, \cdots, n .
$$

Table 5 shows the results of normalized matrix.

\section{Table 5}

Normalized decision matrix

\begin{tabular}{llllll}
\hline Hospital & Tangibles & Reliability & Responsiveness & Assurance & Empathy \\
\hline A & 0.547864239 & 0.525320011 & 0.510357088 & 0.526192185 & 0.498127901 \\
B & 0.507861594 & 0.504882861 & 0.479728617 & 0.481605153 & 0.506935476 \\
C & 0.47089823 & 0.495487806 & 0.504289523 & 0.47942252 & 0.490577314 \\
D & 0.469229404 & 0.472889011 & 0.505062544 & 0.511206718 & 0.504201265 \\
\hline
\end{tabular}

Second step: the normalized weight matrix is calculated by the following formula and by weight vectors which were calculated in the AHP method as follows,

$V_{i j}=w_{i} \times r_{i j}, j=1, \cdots, J ; i=1, \cdots, n$.

Table 6

Normalized weight matrix

\begin{tabular}{llllll}
\hline Hospital & Tangibles & Reliability & Responsiveness & Assurance & Empathy \\
\hline A & 0.152854 & 0.075646 & 0.07145 & 0.076824 & 0.145453 \\
B & 0.141693 & 0.072703 & 0.067162 & 0.070314 & 0.148025 \\
C & 0.131381 & 0.07135 & 0.070601 & 0.069996 & 0.143249 \\
D & 0.130915 & 0.068096 & 0.070709 & 0.074636 & 0.147227 \\
\hline
\end{tabular}

Third step: in this step ideal and negative ideal solutions of each index are calculated as follow, 


$$
\begin{aligned}
& A^{+}=\left\{v_{1}^{+}, \cdots, v_{i}^{+}\right\}=\left\{\left(\max _{j} v_{i j} \mid i \in I^{\prime}\right),\left(\min _{j} v_{i j} \mid i \in I^{\prime \prime}\right)\right\}, \\
& A^{-}=\left\{v_{1}^{-}, \cdots, v_{i}^{-}\right\}=\left\{\left(\min _{j} v_{i j} \mid i \in I^{\prime}\right),\left(\max _{j} v_{i j} \mid i \in I^{\prime \prime}\right)\right\},
\end{aligned}
$$

where I' is associated with benefit items and I'’ is associated with expense items.

$A^{+}=\{0.152854,0.075646,0.07145,0.076824,0.148025\}, A^{-}=\{0.130915,0.068096,0.067162,0.069996,0.143249\}$.

Fourth step: distance of each option to ideal and not ideal solutions are calculated as follows,

$$
\begin{aligned}
& D_{j}^{+}=\sqrt{\sum_{i=1}^{n}\left(v_{i j}-v_{i}^{+}\right)^{2}}, j=1, \cdots, J ; D_{j}^{-}=\sqrt{\sum_{i=1}^{n}\left(v_{i j}-v_{i}^{-}\right)^{2}}, j=1, \cdots, J \\
& D_{1}^{+}=0.002571812, D_{2}^{+}=0.013927899, D_{3}^{+}=0.023446324, D_{4}^{+}=0.023330282, \\
& D_{1}^{-}=0.02466177, D_{2}^{-}=0.012661607, D_{3}^{-}=0.004751255, D_{4}^{-}=0.007066798 .
\end{aligned}
$$

Fifth step: proportional distance of each option to ideal solution is calculated based on the ideal solutions,

$$
C C_{j}^{+}=\frac{D_{j}^{-}}{D_{j}^{+}+D_{j}^{-}}, j=1, \cdots, J,
$$

which yields $\quad C C_{1}^{+}=0.905564684, C C_{2}^{+}=0.476188283, C C_{3}^{+}=0.168671762, C C_{4}^{+}=0.232482788$. This means that hospital A receives the best ranking with 0.91, hospital $\mathrm{B}$ stays in the second position in terms of ranking, hospital $\mathrm{D}$ is in the third position and hospital $\mathrm{C}$ is in the last position. In other words, hospital A has the best quality between these four hospitals and then there are hospital B, D and C.

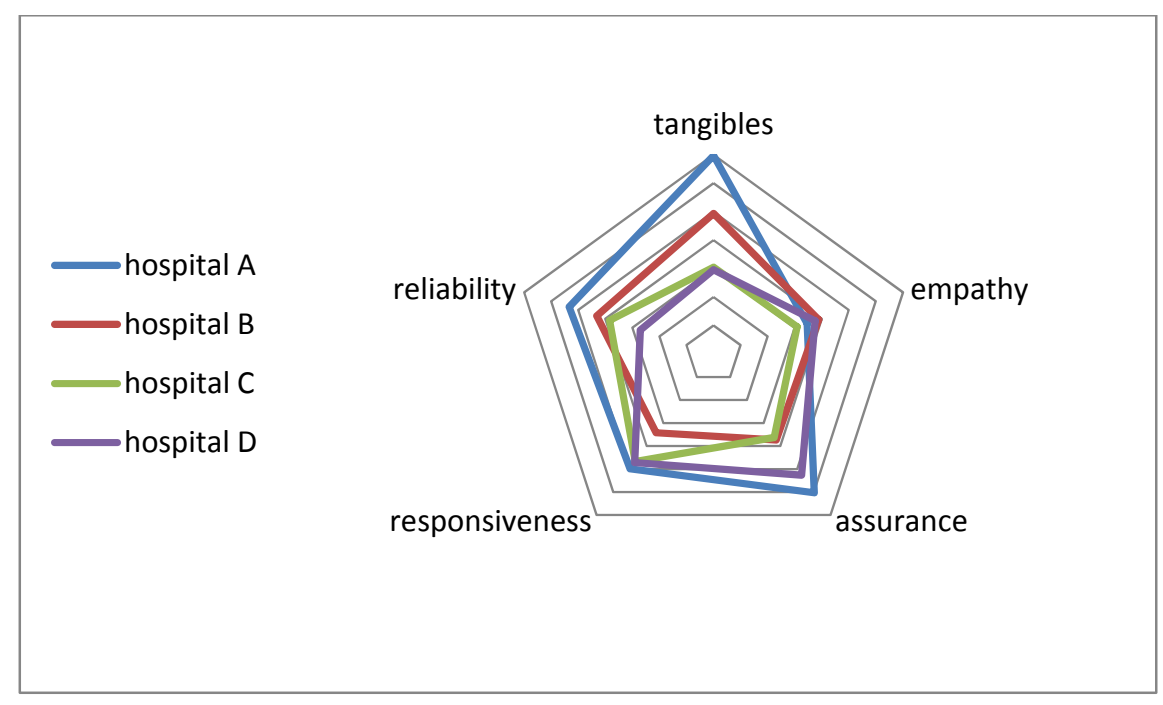

Fig. 2. The position of each hospital in each dimension of service quality

Fig. 2 makes the comparison of each dimension in various hospitals; possible. Hospital managers can recognize their strength and weakness points by using this comparison in the field of quality service. They can also compare themselves with other competitors in each dimension, and they can do urgent actions in order to have no fault and improve the service quality of their hospitals.

\subsection{Solution}

In this part, we express different solutions for improving the quality of service for each hospital based on the grade of the quality of service. 


\subsubsection{First grade}

Hospital A is the first in among four hospitals and it has received the first grade in four out of five dimensions. It shows that this hospital's strength points are more than others. As we can observe from Fig. 2, this hospital is in the third grade based on the dimension of empathy and as it is shown by the weights of criteria that empathy has the highest weight. Therefore, hospital A should improve the quality of this dimension.

\subsubsection{Second grade}

The distance of hospital B from an ideal hospital is about 0.5 , which shows that the level of service quality in this hospital is balanced and normal. Being in grade 1 in the dimension of empathy is a strength point of this hospital, according to the critical importance of this dimension. However, this hospital is in the third and fourth grades in the dimensions of assurance and responsiveness, respectively. These grades show hospital's weakness points. If the managers of these hospitals want to improve the quality of their services, they should try to succeed in these criteria. Since assurance has more weight, at first they should improve the dimension of assurance (0.146) and improving the dimension of responsiveness (0.14) must be considered.

\subsubsection{Third grade}

The grade of hospital D is about $80 \%$ less than the grade of an ideal hospital. It is observed that this hospital has the least grade in two dimensions of tangibles and reliability. Hospital managers should pay more attention to the apparent quality of service and then they should improve the dimension of reliability.

\subsubsection{Fourth grade}

Hospital C has the least grade of the quality of service. It has the third grade in the dimensions of tangibles, reliability and responsiveness and it is in the least or fourth grade in the dimensions of empathy and assurance. This hospital should try to improve the quality of its service in all of the dimensions and it should try to have a better condition in supplying the service in all of dimensions.

\section{Conclusion}

In this paper, we have presented an empirical study on ranking four hospitals based on fuzzy TOPSIS method. The proposed model of this paper considered five criteria of tangible, reliability, responsiveness, assurance and empathy and using analytical hierarchy process prioritize them. The results yields different values for empathy with the weight coefficient (0.292) was the most important criterion and then tangibles (0.279), assurance $(0.146)$, reliability $(0.144)$ and responsiveness $(0.14)$ were the most important criterions respectively. We have used fuzzy numbers to overcome the ambiguity of decision makers' opinion and the fuzzy numbers were converted into crisp values. The final results of the implementation of TOPSIS indicate that hospital A received the best ranking with 0.91, hospital B was in the second position in terms of ranking, hospital D was in the third position and hospital $\mathrm{C}$ was in the last position.

\section{References}

Andaleeb, S. S. (2001). Service quality perceptions and patient satisfaction: a study of hospitals in a developing country. Social Science \& Medicine 52, 1359-1370.

Athanassopoulos, A., \& Podinovski, V. (1997). Dominance and potential optimality in multiple criteria decision analysis with imprecise information. Journal of Operational Research Society, 48 ,142-150.

Benitez, J. M., Martın, J. C., \& Roman, C. n. (2007). Using fuzzy number for measuring quality of service in the hotel industry. Tourism Management, 28, 544-555. 
Chang, Y.-H., \& Yeh, C.-H. (2001). Evaluating airline competitiveness using multiattribute decision making. Omega, 29(5), 405-415.

Chen, S., \& Hwang, C. (1991). Fuzzy Multiple Attribute Decision Making: Methods and Applications. New York: Springer-Verlag.

Chien, C., \& Tsai, H. (2000). Using fuzzy numbers to evaluate perceived service quality. Fuzzy Sets and Systems, 116, 289-300.

Chiena, C.-J., \& Tsaia, H.-H. (2000). Using fuzzy numbers to evaluate perceived service quality. Fuzzy Sets and Systems, 116, 289-300.

Cronbach, L. J. (1951). Coefficient alpha and the internal structure of tests. Psychometrika, 16(3), 297-334.

Dabholkar, P. A., Thorpe, D., \& Rentz, J. (1996). A measure of service quality for retail stores: scale development and validation. Journal of the Academy of Marketing Science, 24(1), 3-16.

Gilbert, F. W., Lumpkin, J. R., \& Dant, R. P. (1992). Adaptation and customer expectation of health care options. Journal of Health Care Marketing, 12(3), 46-55.

Guldner, \& Rifkin. (1993). Sustainability in the Health Sector, part 1: Vietnam Case Study. London.

Ham, L. (2003). Analyzing the value of service quality management: gaining competitive advantages. International Journal of Value-Based Management, 16, 131-152.

Herrera, F., \& Viedma, E. (2000). Linguistic decision analysis steps for solving decision problems under linguistic information. Fuzzy Sets and Systems, 115(1), 67-82.

Hsiao, S. (1998). Fuzzy logic based decision model for product design. International Journal of Industrial Ergonomics, 21, 103-116.

Hu, Y.-C. (2009). Fuzzy multiple-criteria decision making in the determination of critical criteria for assessing service quality of travel websites. Expert Systems with Applications, 36, 6439-6445.

Hutchinson, M. O. (1998). The use of fuzzy logic in business decisionmaking. Derivatives Quaterly, 4(4),53-67.

Hwang, C., \& Yoon, K. (1981). Multiple Attribute Decision Making: Methods and Applications. New York: Springer-Verlag.

Lafond, A. (1995). Improving the Quality of Investment in Health: Lessons on Sustainability.

Liou, T., \& Wang, M. (1992). Ranking fuzzy numbers with integral value. Fuzzy Sets and Systems, 50, 247-55.

Liou, T., \& Wang, M. (1994). Subjective assessment of mental workload - a fuzzy linguistic multicriteria approach. Fuzzy Set and Systems, 62, 155-65.

Liou, T.-S., \& Chen, C.-W. (2006). Subjective appraisal of service quality using fuzzy linguistic assessment. International Journal of Quality \& Reliability Management, 23(8), 928-943.

Magi, A., \& Julander, C. (1996). Perceived service quality and customer satisfaction in a store performance framework. Journal of Retailing and Consumer Services, 3(1), 33-41.

Michael, D. C., Lucie, K. O., \& Walter, L. L. (2001). Patients' perceptions of service quality dimensions:an empirical examination of health care in New Zealand. Health Marketing Quarterly, 19(1), 3-22.

Nakamori, Y., Sato, K., \& Watada, J. (1997). Fuzzy space model for fuzzy data. Journal of Japan Society for Fuzzy Theory and Systems, 9(1), 99-107.

O’Connor, S. J., Shewchuk, R. M., \& Carney, L. W. (1994). The great gap. Journal of Health Care Marketing, 14(2), 32-39.

Parasuraman, A., Zeithaml, V., \& Berry, L. (1985). A conceptual model of service quality and its implications for future research. Journal of Marketing, 49 (4), 41-50.

Parasuraman, A., Zeithaml, V., \& Berry, L. (1988). SERVQUAL:A multiple-item scale for measuring consumer perception of service quality. Journal of Retailing, 64 (1), 12-40.

Parikh, D. (2005). Measuring retail service quality: an empirical study in a developing country. South Asian Journal of Management, 12(2), 43-57.

Petersen, M. B. (1988). Measuring patient satisfaction:collecting useful data. Journal of Nursing Quality Assurance, 2(3), 25-35. 
Prascevic, Z., \& Petrovic-Lazarevic, S. (1997). Determination of optimal bidding profit rate by fuzzy set theory. Cybernetics and Systems, 28(4), 337-343.

Prascevic, Z., \& Petrovic-Lazarevic, S. (1998). Fuzzy multiple objective decision making in the construction industry. Monash University, Department of Management, working pape, 90-98.

Prascevic, Z., \& Petrovic-Lazarevic, S. (1996). Probabilistic- possibilistic approach to the optimal selection of a contractor. Journal of Operational Research, 6(1), 137-141.

Roger, F. B., Ian, N. L., \& Martina, A. B. (1999). Internal marketing and customer driven wavefronts. The Service Industries Journal, 19(4), 49-67.

Ryan, C., \& Trauer, B. (2003). Involvement in adventure tourism: toward implementing a fuzzy set. Tourism Review International, 7(3-4) , 143-52.

Saaty, T. L. (1980). The analytic hierarchy process: planning, priority setting. New York: McGraw Hill International Book Co.

Shawyer, R. J. (1996). The role of clinical vignettes in rapid ethnographic research: A folk taxonomy of diarrhea in Thailand. Social Science \& Medicine, 42(1), 111-123.

TSAI, M.-T., WU, H.-L., \& LIANG, W.-K. (2008). Fuzzy Decision Making for Market Positioning and Developing Strategy for Improving Service Quality in Department Stores. Quality \& Quantity , 42, 303-319.

Tsaura, S.-H., Changb, T.-Y., \& Yena, C.-H. (2002). The evaluation of airline service quality by fuzzy MCDM. Tourism Management, 23, 107-115.

Ufek, C., \& Ahmet, B. (2002). An approach to the evaluation of quality performance of the companies in Turkey. Managerial Auditing Journal, 92-100.

Viswanathan, M. (1999). Understanding how product attributes influence product categorization: development and validation of fuzzy set-based measures of gradedness in product categories. Journal of Marketing Research, 36(1), 75-95.

Wang, E. J. (2002). Outage costs and strategy for hi-tech industries: a fuzzy multiple goal approach. The International Journal of Quality \& Reliability Management, 19(8/9), 1068-1087.

Wu, C. R., Lin, C. T., \& Chen, H. C. (2007). Optimal selection of location for Taiwanese hospitals to ensure a competitive advantage by using the analytic hierarchy process and sensitivity analysis. Building and Environment, 42(3),1431-1444.

Wu, W.-Y., Hsiao, S.-W., \& Kuo, H.-P. (2004). Fuzzy Set Theory Based Decision Model for Determining Market Position and Developing Strategy for Hospital Service Quality. Total Quality Management, 15(4), 439-456.

Xia, X., Wang, Z., \& Gao, Y. (2000). Estimation of non-statistical uncertainty using fuzzy-set theory. Measurement Science and Technology, 11(4), 430-435.

Yeh, C.-H., \& Kuo, Y.-L. (2003). Evaluating passenger services of Asia-Pacific international airports. Transportation Research Part E, 39, 35-48.

Yeh, C.-H., Deng, H., \& Chang, Y.-H. (2000). Fuzzy multicriteria analysis for performance evaluation of bus companies. European Journal of Operational Research, 126 (3), 459-473.

Yeh, C.-H., Deng, H., \& Pan, H. (1999a). Multi-criteria analysis for dredger dispatching under uncertainty. Journal of the Operational Research Society, 50(1), 35-43.

Zadeh, L. A. (1965). Fuzzy set. Information and Control, 8, 338-353.

Zeithaml, V. A., \& Bitner, M. J. (2000). Services marketing. New York: McGraw-Hill .

Zeleny, M. (1998). Multiple criteria decision making: eight concepts of optimality. Human Systems Management, 17(2), 97-107.

Zhou, D., Ma, D., \& Efraim, M. (2001). Journal quality assessment: an integrated subjective and objective approach. IEEE Transactions on Engineering Management, 48(4), 479-490.

Zimmermann, H. J. (1996). Fuzzy set theory and its applications. Boston: Kluwer Academic Publishers. 